\section{Clozapine for the treatment of levodopa- induced psychosis and dyskinesia in Parkinson's disease}

Sir - Jalenques and Coudert ${ }^{1}$ present a very interesting case study and review of the literature on the use of clozapine in the treatment of levodopa-induced psychosis and dyskinesia in Parkinson's disease.

We were, however, surprised by the omission of any explicit reference to the risk of agranulocytosis with clozapine. This rare but potentially fatal side effect is of considerable interest to clinicians. A fatality rate of up to one in 300 has been estimated prior to the introduction of routine blood monitoring. ${ }^{2}$ Because of this serious unwanted effect, clozapine is indicated only in patients unresponsive to, or intolerant of, conventional antipsychotic drugs. ${ }^{3}$

It is the clinical experience of one of us that such patients can often be managed with conventional antipsychotic drugs, which have the additional advantage of being considerably cheaper than clozapine.

Other antipsychotic drugs are available for the treatment of psychosis in Parkinson's disease, such as sulpiride, which have less pronounced extrapyramidal side-effects. It is our view that such drugs should be used before resorting to clozapine.

\section{TA Hughes, RHS Mindham, HF Ross,}

Division of Psychiatry and Behavioural Sciences, School of Medicine, University of Leeds, 15 Hyde Terrace, Leeds LS2 9LT, England.

\section{References}

1. Jalaenques L, Coudert AJ. Clozapine for the treatment of levodopa induced psychosis and dyskinesia in Parkinson's disease. Ir J Psychol Med, 1994; 11:8388 .

2. ABPI Data Sheet Compendium. Datapharm Publications Limited, 1994-5; 1377.

3. British National Formulary. British Medical Association and Royal Pharmaceutical Association of Great Britain. 1994; 150.

\section{Authors' reply}

Sir - Hughes, Mindham and Ross emphasise the guidelines concerning prescriptions of clozapine which is indicated only in patients unresponsive to, or intolerant of, conventional antipsychotic drugs. Obviously, if patients can be managed with conventional neuroleptics, the use of clozapine should not be considered.

We are, however, surprised by the incidence of agranulocytosis these authors underline. Recent data by Alvir and Lieberman ${ }^{1}$ should be mentioned: the Clozaril Patient Management System reported two patients who died after developing agranulocytosis in the cohort of 11,555 patients who received clozapine in the United States from February 1990 to April 1991. The haematologic monitoring system, both necessary and effective, induces greater effort and costs than conventional neuroleptics. But an exact evaluation needs to take into account a global cost including duration of hospitalisation, social cost, etc. ${ }^{2}$

The management of levodopa psychoses generally requires first a reduction in parkinsonian medications or a "drug holiday'. Electroconvulsive therapy should also be considered.
An antipsychotic drug should be only added in patients whose psychosis fails to respond to, or who cannot tolerate, a reduction in medication. Such an addition makes sense only if the psychiatric benefits outweigh the adverse effects.

Even low-potency neuroleptics with mild extra-pyramidal adverse effect profiles have been implicated in inducing parkinsonism and even relatively low doses of low-potency neuroleptics have induced marked exacerbation of parkinsonism in idiopathic Parkinson's disease (PD). ${ }^{3}$ In particular, comparative studies of sulpiride in psychiatric patients reported similar extrapyramidal effects when compared to other neuroleptics. ${ }^{4-6}$

The work of Alberts et $\mathrm{al}^{7}$ concerning the adverse effects in 65 clinical trials involving 2,851 patients receiving sulpiride, reported neurological events in 366 patients, among them rigidity, akathisia, acute dystonia and generalised dyskinesia. Thus, it would be of interest to perform and publish comparative studies on sulpiride and other neuroleptics in the treatment of psychosis in PD in order to clarify the clinical experience.

Lastly, while we agree that clozapine must only be used in limited situations, our view is that the lack of acute blockade of striatal D2 receptors and the failure of chronic clozapine treatment to suppress striatal dopamine release may account for the lack of worsening effect on PD; and that a specific benefit of clozapine on parkinsonism might be due to an effect on the serotonergic system leading to a release of striatal dopamine. In some particular cases, such properties can be of great benefit for the treatment of psychosis in patients with PD.

\section{Jalenques, A-J Coudert, Service de psychiatrie de l'adulte et psycholigie medicale, Centre Hospitalier Universitaire, BP 69, 63003 Clermont-FD, Cedex l, France.}

References

1. Alvir JM, Lieberman JA. A revaluation of the clinical characteristics of Clozapine-induced agranulocytosis in light of the United States experience. J Clin Psychopharmacol 1994; 14, lex 2501:87-9.

2. Meltzer HY, Cola P, Way L, Thompson PA, Bastani B, Davies MA, Snitz B. Cost effectiveness of Clozapine in neuroleptic-resistant schizophrenia. Am J Psychiatry 1993; 150;11:1630-83.

3. Murdock PS, Williamson J. A danger in making the diagnosis of Parkinson's disease. Lancet 1982: 2:1212-3.

4. Cassano GB, Castrogiovanni P, Conti L. Sulpiride versus haloperidol in schizophrenia: a double-blind comparative trial. Curr Ther Res 1975; 17: 189-201. 5. Gerlach $J$, Behnke $K$, Heltberg $J$, et al. Sulpride and haloperidol in schizophrenia: a double-blind cross-over study of therapeutic effect, side effects and plasma concentrations. Br J Psychiatry 1985; 147: 283-8.

6. Friefman $J H$. The management of the levodopa psychoses. Clin Neuropharmacol $1991 ; 14: 283-95$.

7. Alberts JL, Francois F, Josserand F. Study of side effects reported in patients under dogmatil (in french). Sem Hop 1985; 61: 1351-7.

\section{The prediction of suicide and the law on abortion}

Sir - In his editorial The prediction of suicide and the law on abortion, ${ }^{1}$ Kelleher concludes that the research evidence (quoted by him) indicates that medicine and psychology does not have the ability to predict suicide, even with a 